07;08

\title{
Исследование квантовых точек в мультизеренном слое планарно-торцевой микроструктуры
}

\author{
( Н.Д. Жуков, И.Т. Ягудин, Н.П. Абаньшин, Д.С. Мосияш \\ ООО „НПП Волга“, Саратов, Россия \\ E-mail: ndzhukov@rambler.ru
}

Поступило в Редакцию 22 мая 2020 г.

В окончательной редакции 22 мая 2020 г.

Принято к публикации 28 июля 2020г.

Исследованы квантовые точки (КТ) полупроводников $\mathrm{CdSe}, \mathrm{PbS}, \mathrm{InSb}$ в мультизеренном слое планарноторцевой микроструктуры. Рассмотрена модель упорядоченного расположения КТ в микронном зазоре структуры и протекания тока по линиям их последовательно-параллельного расположения. Электронный транспорт при малых величинах напряжения (менее $8 \mathrm{~V}$ ) определяется термо- и туннельной эмиссией из КТ в зазор, при больших - зарядовым ограничением в КТ по модели кулоновской блокады. Обнаружено сильное влияние на вольт-амперные характеристики излучения ИК- и УФ-спектров.

Ключевые слова: квантовая точка, мультизеренный слой, планарно-торцевая микроструктура, электронный транспорт, туннельная эмиссия, кулоновская блокада.

DOI: 10.21883/PJTF.2020.21.50196.18392

Исследование свойств и возможностей применения квантово-размерных частиц (квантовых точек, КТ) активно развиваемое направление науки и техники [1]. Успехи их применения, однако, далеки от ожидаемых. Одной из причин этого являются нерешенные проблемы приборных квантово-размерных частиц (квантовых точек), позволяющих эффективно их расположить, подвести питающие электроды, законсервировать и использовать в конкретных вариантах приборов. Для исследований свойств КТ используются, как правило, простые варианты плоских подложек из диэлектриков и полупроводников. Для их применения, однако, требуются специальные варианты подложек, ряд из которых известен из литературы, например, плоские подложки с встречно-штыревыми электродами [2] и стеклоуглеродным электродом [3]), точное наноразмерное позиционирование излучающего элемента [4], мультиканальная структура [5], трехмерное расположение нанокристаллов на границе этиленгликоль-воздух [6], а также в виде пленки Ленгмюра-Блоджетт [7].

Целью настоящей работы являются поиск и исследование варианта микроструктуры-носителя квантовых точек на простой подложке, перспективной в качестве элемента приборов, например, источников и приемников инфракрасного излучения.

В работе использована разработанная нами для автокатода полевой эмиссии так называемая планарноторцевая структура (ПТС) [8]. Ее схема и электронный фотоснимок приведены на рис. $1, a, b$. Преимущества такой структуры перед указанными выше заключаются в том, что ее изготовление базируется на планарной технологии микроэлектроники относительно простого уровня и при этом можно получить реальную элементную базу, основанную на принципах одноэлектроники.
С помощью методов технологии микроэлектроники изготовлена тестовая структура со следующими параметрами: зазор между планарно-торцевыми электродами $1 \mu \mathrm{m}$, ширина узкой полоски (M2, катод) $30 \mu \mathrm{m}$, широкой $(M 1$, анод) $160 \mu \mathrm{m}$, расстояние между полосками $15 \mu \mathrm{m}$, количество полосок 121 , длина области пересечения $180 \mu \mathrm{m}$. Площадь одной катодной полоски составляет $0.468 \mathrm{~mm}^{2}$, всех катодных полосок - $56 \mathrm{~mm}^{2}$.

Для ПТС в качестве управляющих электродов и подводящих шин использован молибден. Разделяющим и изолирующим слоем является оксид кремния. Катод ПТС имеет композитную структуру и состоит из тонкой пленки алмазоподобного гидрогенизированного углерода, нанесенного на поверхность плеки молибдена. Основным критерием выбора материалов для слоев ПТС является различие свойств их селективных травителей: должен травиться только нужный слой с минимальным подтравом соседних. При этом используется метод самосовмещения, когда предыдущий слой является маской для последующего. Металлические пленки наносились методом магнетронного осаждения из плазмы газового разряда (PECVD). C применением фотолитографии формировались общая геометрия структуры, подводящие шины и контактные площадки. Далее формировалась прецизионная объемная микроструктура области катод-анод с использованием последовательного жидкостного и плазменного травления в режиме „стоп-слоя“.

На поверхность ПТС наносился сплошной слой квантовых точек из раствора летучей жидкости (спирты) капельным методом с последующей сушкой под накальной лампой в несколько приемов. После каждого приема микроскопически контролировались общий вид и морфология слоя, а также вольт-амперная характеристика 

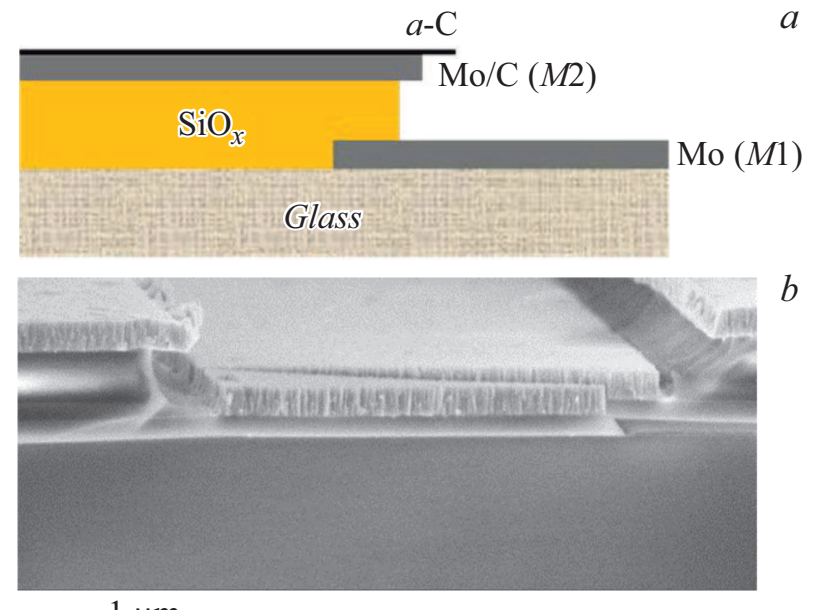

$-1 \mu \mathrm{m}$
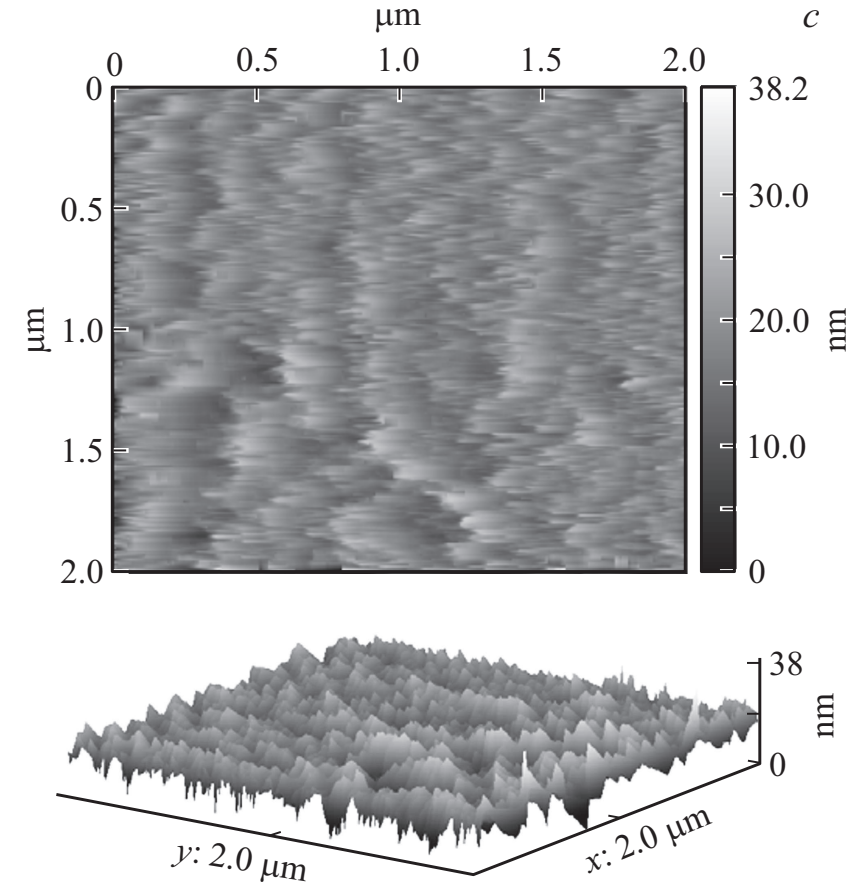

Pис. 1. Фрагменты планарно-торцевой структуры: $a-$ схема, $b-$ фотоснимок на сканирующем электронном микроскопе; $c$ - CТМ-топограмма поверхности слоя квантовых точек InSb.

(BAX). Процесс заканчивался, когда слой становился сплошным с максимальной упаковкой наночастиц, а BAX имела форму кривой, обычной для неоднородной полупроводниковой структуры. Морфология слоя и степень упаковки наночастиц в нем контролировались на сканирующем туннельном микроскопе (СТМ) (рис. 1,c).

Процесс формирования слоя из раствора наночастиц в летучей жидкости является самоорганизующимся [9]. Движущей силой, инициирующей процесс упорядочения наночастиц в капле и в формируемом слое, является испарение растворителя и связанное с этим изменение объема системы, приводящее к возникновению микропотоков гидродинамической, диффузионной и тепловой природы. Кроме того, в нашем случае оказывают влияние конфигуративность микроструктуры ПТС (рис. $1, a, b)$ и возможность управлять процессом с помощью электрического поля в зазоре катод-анод. Сформированную структуру слоя мы назвали мультизеренной (МЗС) [10] по аналогии с названием, используемым для нанопорошков металлов и композитных материалов (MGS) [11].

Наши исследования оптических свойств и люминесценции квантовых точек в мультизеренной структуре показали, что они аналогичны свойствам КТ в коллоидном растворе с определенными поправками по спектрам и интенсивности [12,13].

В настоящей работе нами проведены измерения и модельный анализ механизмов электронного транспорта в МЗС ПТС с квантовыми точками полупроводников $\mathrm{CdSe}, \mathrm{PbS}, \mathrm{InSb}$, синтезированными по технологии, описанной в работе [14], при соответствующих коррективах состава и режимов. Ядро квантовых точек окружено оболочкой $\mathrm{CdS}$ толщиной не более шести атомных слоев.

Рассматриваемые структуры можно было бы отнсти к неупорядоченным полупроводникам [15]. Однако в отличие от последних, которые обладают плотной упаковкой с нулевыми зазорами между кристаллитами, рассматриваемые нами структуры имеют объемные зазоры между кристаллитами. Если для неупорядоченных полупроводников основным для преодоления границ является механизм электронного перескока, то в нашем случае необходимо принять модель транспорта электронов посредством эмиссионного или туннельного преодоления зазора, последовательных с ним инжекции и дрейфа в объеме квантовой точки, т.е. проводящая структура представляет собой последовательно-параллельные цепочки квантово-размерных частиц неправильной формы. При этом их контактное соединение может иметь развличную геометрию, в том числе и с нулевым зазором.

Измерения BAX проводились с использованием нестандартного генератора однополярного низкочастотного импульсного пилообразного напряжения по методике, описанной в нашей работе [10].

На рис. 2 представлены ВАХ в координатах $\ln I \propto V$ и $\ln I \propto V^{-1}$ для интервала напряжений до $8 \mathrm{~V}$. Построения и анализ выполнены с использованием программы Excel. Аппроксимация с высокой достоверностью позволила установить применимость формул: для КТ CdSe $I \propto \exp \left(A_{E} V / T\right)$, для $\mathrm{PbS}-I \propto \exp \left(A_{T} V\right)$, для $\mathrm{InSb}-$ $I \propto \exp (B V)$ (величины параметров указаны в подписи к рисунку). Исходя из обычной методики использования этих формул $[10,16]$ можно считать, что каждому из вариантов соответствуют следующие механизмы транспорта электронов: для КT CdSe - термоэмиссия, для $\mathrm{PbS}$ - прямое (со дна зоны проводимости) туннелирование, для $\mathrm{InSb}$ - туннелирование из локализованных состояний. 


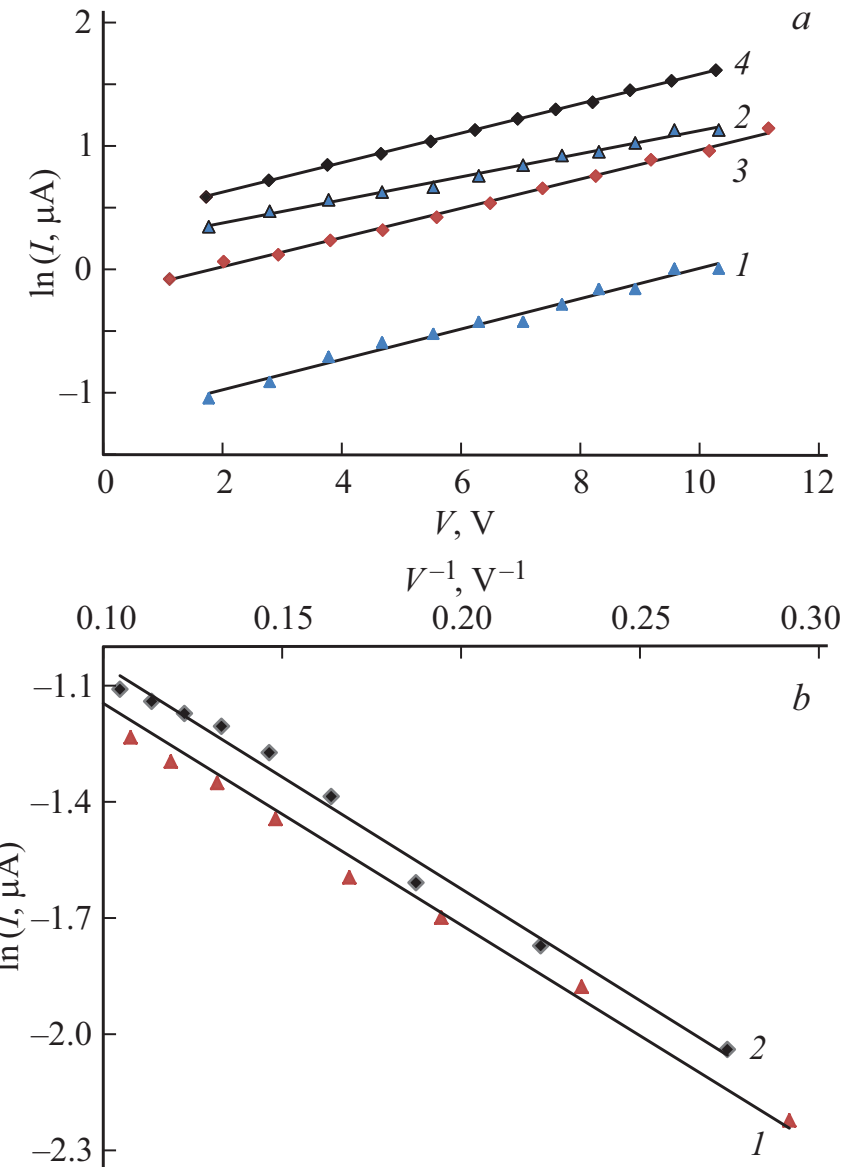

Рис. 2. Вольт-амперные характеристики МЗС („плюс“ на катоде). a) $1-\mathrm{CdSe}\left(300 \mathrm{~K}, A_{E} \sim 0.12\right), 2-\mathrm{CdSe}(360 \mathrm{~K}$, $\left.A_{E} \sim 0.09\right), 3-\mathrm{PbS}\left(300 \mathrm{~K}, A_{T} \sim 0.119\right), 4-\mathrm{PbS}(360 \mathrm{~K}$, $\left.\left.A_{T} \sim 0.115\right) ; b\right) \mathrm{InSb}, B \sim 5.75(1-300 \mathrm{~K}, 2-360 \mathrm{~K})$.

На рис. 3 приведены типичные ВАХ в билогарифмическом масштабе для интервала величин напряжения $>8 \mathrm{~V}$. Для всех кривых выполняется зависимость $I \propto V^{m}$. При этом $m \approx 1.50 \pm 0.15$ для всех случаев, кроме кривой 3 , для которой $m \approx 1$. Данный результат свидетельствует о том, что ВАХ в этом интервале напряжений лимитируется транспортом электронов через квантовые точки с его ограничением пространственным зарядом (ТОПЗ) [10]. При этом независимо от различий (тип полупроводника, полярность, температура) аппроксимация практически одинакова, т.е. механизм транспорта постоянен.

На BAX для образцов $\mathrm{InSb}$ и $\mathrm{PbS}$ в некотором интервале напряжений $V>V_{\text {crit }}$ отмечаются участки провала (кривые 1 и 7 на рис. 3), а также явно разная зависимость от засветки образцов инфракрасным (ИК) и ультрафиолетовым (УФ) светом (кривые 3 и 6). Кроме того, в рассматриваемом варианте наблюдается некая несимметричность ВАХ по полярности (кривые 1 и 2) в отличие от варианта встречно-штыревой структуры [10], что можно объяснить несимметричностью геометрии электродов в микроструктуре.
Объяснение полученных результатов предложено нами на основе следующей модели структуры: КТ группируются в ее микронном зазоре катод-анод (рис. $1, a, b)$, упорядоченно собираясь (рис. 1,c) и образуя последовательно-параллельные наноэлементы по линиям тока. Выделив структурный элемент в виде куба с ребром $1 \mu \mathrm{m}$, легко показать, что число последовательных наночастиц в линии тока $N \propto R_{\mathrm{LC}} / R_{\mathrm{QD}}$, где $R_{\mathrm{QD}}-$ сопротивление отдельной КТ, а $R_{\mathrm{LC}}-$ сопротивление их последовательности в линии тока. На туннельном микроскопе нами измерены величины $R_{\mathrm{QD}}$ для всех вариантов КТ: $R_{\mathrm{QD}} \propto 120 \pm 10 \mathrm{M} \Omega$. По ВАХ с пересчетом на удельную площадь найдены значения $R_{\mathrm{LC}}$ и примерные размеры периода расположения КТ в линии (указаны в скобках), сопоставимые с размером КТ: для КТ $\mathrm{CdSe}-\sim 550 \mathrm{M} \Omega, N \approx 450(2-3 \mathrm{~nm})$, для $\mathrm{PbS}-300 \mathrm{M} \Omega, N \approx 250(5-6 \mathrm{~nm})$, для $\mathrm{InSb}-$ $350 \mathrm{M} \Omega, N \approx 280(4-5 \mathrm{~nm})$. Эти результаты характеризуют прецизионность микроструктуры, в которой КТ могут самоорганизоваться в зазоре микронного размера, а остальной частью пленки защитить (законсервировать) этот микрообъем от внешних воздействий.

В механизме тока интересными являются результаты электронного транспорта в случаях полярности „минус“ на катоде (рис. 3). Общий для всех вариантов механизм (ТОП3) может определяться так же, как и для отдельной КТ: с проявлениями кулоновской блокады и характерных провалов на ВАХ (кулоновская щель) в виде участков отрицательного сопротивления (кривые 1 и 7 на рис. 3). Характерное напряжение проявления и критическое напряжение $V_{Q}$ описываются выражением [17]:

$$
V \gg V_{Q}=q(n+1 / 2) C^{-1},
$$

где $q$ - заряд электрона, $n$ - число блокирующих электронов в КТ, $C$ - емкость КТ. Бо́льшие значения $C$ для $\mathrm{PbS}$, чем для $\mathrm{InSb}$, определяют разницу для них в величинах $V_{Q}$ (кривые 1 и 7 на рис. 3).

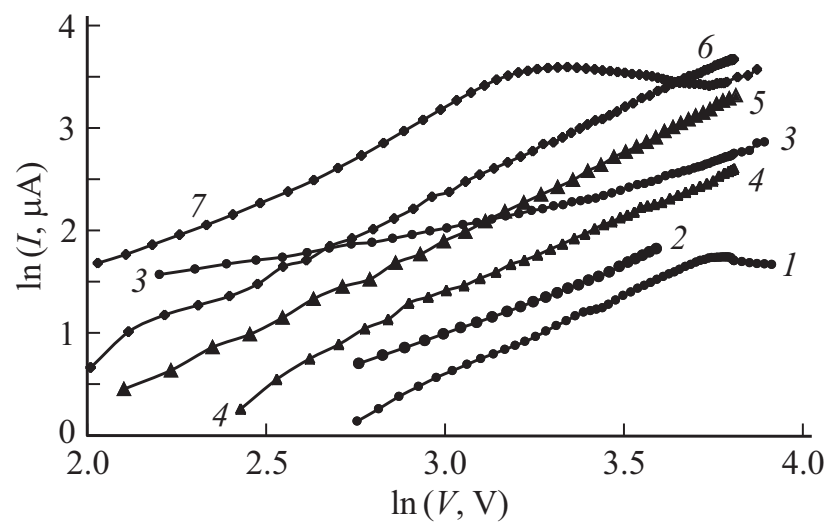

Рис. 3. Вольт-амперные характеристики МЗС („минус“ на катоде). 1 - InSb, $2-\mathrm{InSb}$ („плюс“ на катоде), 3 - InSb (с ИК-засветкой $), 4-\mathrm{CdSe}, 5-\mathrm{CdSe}(350 \mathrm{~K}), 6-\mathrm{PbS}$ (с УФ-засветкой), $7-\mathrm{PbS}$. 
Исследованы воздействия светом на структуру (кривые 3 и 6 на рис. 3). Для InSb воздействие ИК-излучением $(2 \mu \mathrm{m})$ увеличивает ток (кривые 1 и 3 на рис. 3$)$, а для $\mathrm{PbS}$ воздействие УФ - уменьшает (кривые 6 и 7 на рис. 3). Это можно объяснить тем, что в КT PbS возбуждаются неравновесные электроны, способные к ТОПЗ на ее границе и, таким образом, увеличению блокирующего заряда в КТ без изменения механизма транспорта. В КТ $\mathrm{InSb}$, имеющей более высокие параметры размерного квантования, электрон более подвижен, и лимитирующий транспорт механизм может смениться, например, на процесс перезарядки наноконденсатора, о чем может свидетельствовать линейность ВАХ (кривая 3 на рис. 3). При этом ток уже не определяется кулоновской блокадой.

Таким образом, в работе показана принципиальная возможность использования микронного планарноторцевого двухэлектродного зазора с квантовыми точками как приборного элемента. На такой элементной базе может быть изготовлена, например, ИК-фотоприемная матрица микронного разрешения. Ее преимущества будут заключаться в том, что она не требует охлаждения и, работая на основе одноэлектронного (однофотонного) принципа, будет иметь высокую фоточувствительность.

\section{Благодарности}

Авторы благодарны профессору А.Г. Рокаху за полезные обсуждения и советы.

\section{Финансирование работы}

Исследование выполнено при финансовой поддержке Российского фонда фундаментальных исследований в рамках научного проекта 19-07-00595-а (исследования свойств КТ) и Фонда содействия в рамках проекта 6823/С3-48354 программы СТАРТ (планарно-торцевая структура).

\section{Конфликт интересов}

Авторы заявляют, что у них нет конфликта интересов.

\section{Список литературы}

[1] Васильев Р.Б., Дирин Д.Н. Квантовые точки: синтез, свойства, применение. Методические материалы. М.: ФНМ МГУ, 2007. $34 \mathrm{c}$.

[2] Жуков Н.Д., Ягудин И.Т. // Микро- и нанотехнологии в электронике. Материалы X Междунар. науч.-техн. конф. Нальчик: КБГУ, 2018. С. 207-210.

[3] Rahman M.M., Karim M.R., Alam M.M., Zaman M.B., Alharthi N., Alharbi H., Asiri A.M. // Sci. Rep. 2020. V. 10. P. 557. https://doi.org/10.1038/s41598-019-57091-6

[4] Dhawan A.R., Belacel C., Esparza-Villa J.U., Nasilowski M., Wang Z., Schwob C., Hugonin J.-P., Coolen L., Dubertret B., Senellart P., Maitre A. // Light: Sci. Appl. 2020. V. 9. P. 33. https://doi.org/10.1038/s41377-020-0269-0
[5] Шишкин М.И., Ягудин И.Т. // Микро- и нанотехнологии в электронике. Материалы X Междунар. науч.-техн. конф. Нальчик: КБГУ, 2018. С. 340-344.

[6] Geuchies J.J., Soligno G., Geraffy E.C., Hendrikx P., van Overbeek C., Montanarella F., Slot M.R., Konovalov O.V., Petukhov A.V., Vanmaekelbergh D. // Commun. Chem. 2020. V. 3. P. 28. https://doi.org/10.1038/s42004-020-0275-4

[7] Chumakov A.S., Al-Alwani A.J.K., Gorbachev I.A., Ermakov A.V., Kletsov A.A., Glukhovskoy E.G., Kazak A.V., Usoltsev N.V., Shtykov S.N. // BioNanoSci. 2017. V. 7. P. 666-671. https://doi.org/10.1007/s12668-017-0449-4

[8] Абаньшин Н.П., Аветисян Ю.А., Акчурин Г.Г., Логинов А.П., Морев С.П., Мосияш Д.С., Якунин А.Н. // Письма в ЖТФ. 2016. Т. 42. В. 10. С. 13-32.

[9] Адрианов В.Е., Маслов В.Г., Баранов А.В., Федоров А.В., Артемьев М.В. // Опт. журн. 2011. Т. 78. № 11. С. 11-19.

[10] Жуков Н.Д., Мосияши Д.С., Синёв И.В., Хазанов А.А., Смирнов А.В., Лапшин И.В. // Письма в ЖТФ. 2017. Т. 43. B. 24. C. $72-79$.

[11] Овчаренко В.Е., Боянгин Е.Н., Мышляев М.М., Иванов Ю.Ф., Иванов К.В. // ФТТ. 2015. Т. 57. В. 7. С. 1270-1276. [Пер. версия: https://doi.org/10.1134/ $\mathrm{S} 1063783415070252]$.

[12] Жуков Н.Д., Кабанов В.Ф., Михайлов А.И., Мосияш Д.С., Хазанов А.А., Шишкин М.И. // ФТП. 2018. Т. 52. В. 1. C. $83-88$.

[13] Жуков Н.Д., Шишкин М.И., Роках А.Г. // Письма в ЖТФ. 2018. Т. 44. В. 8. С. $102-110$.

[14] Крыльский Д.В., Жуков Н.Д. // Письма в ЖТФ. 2019. Т. 45. B. 16. C. $10-13$.

[15] Айвазов А., Будагян Б., Вихров С., Попов А. Неупорядоченные полупроводники. М.: Изд-во МЭИ, 1995. $352 \mathrm{c.}$

[16] Бланк Т.В., Гольдберг Ю.А. // ФТП. 2007. Т. 41. В. 11. C. 1281-1308.

[17] Kurzmann A., Stegmann P., Kerski J., Schott R., Ludwig A., Wieck A.D., König J., Lorke A., Geller M. // Phys. Rev. Lett. 2019. V. 122. P. 247403. https://doi.org/10.1103/PhysRevLett.122.247403 